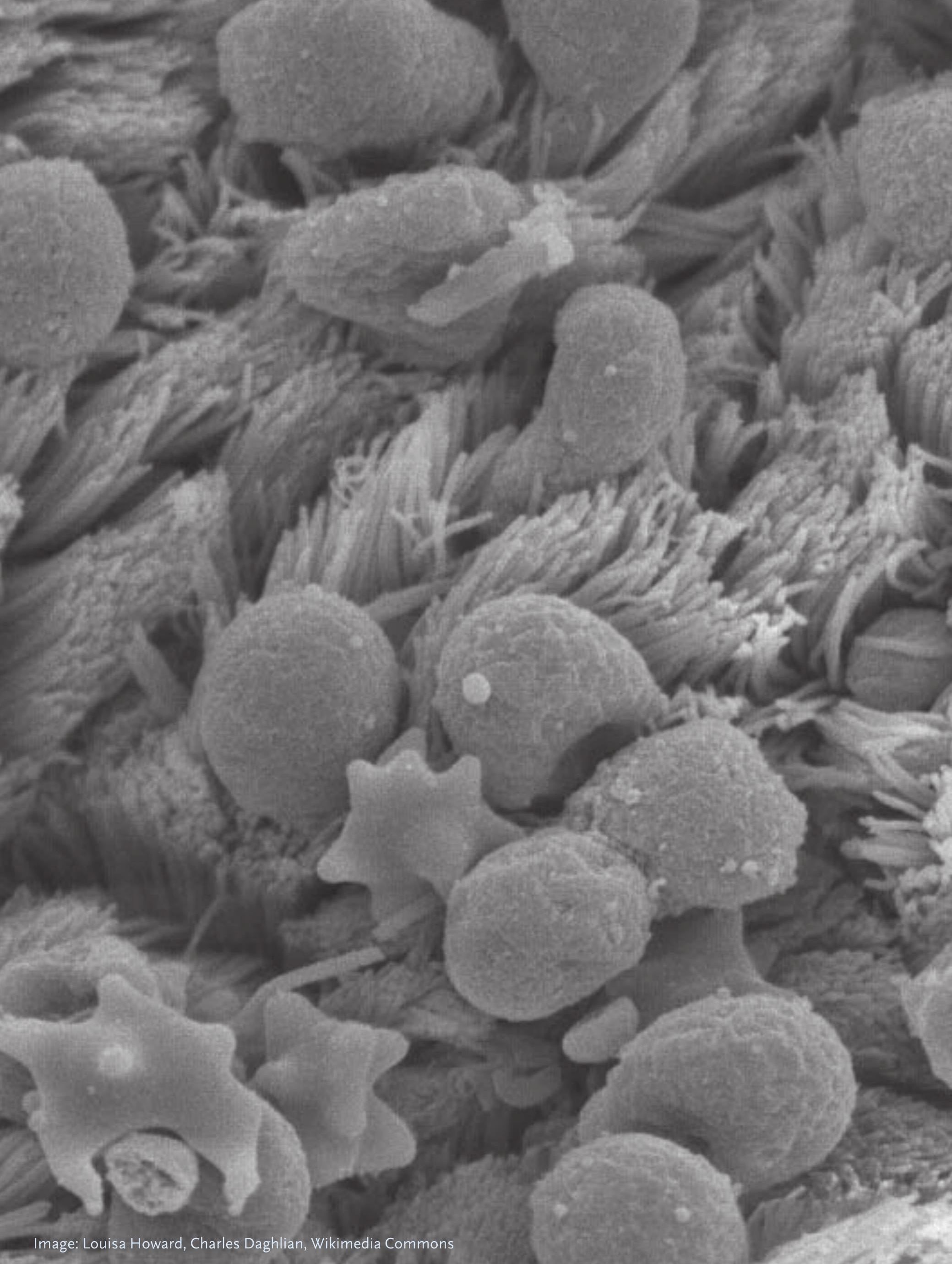




\begin{tabular}{llll}
\hline$\Omega$ & $\square$ & D \\
Mallinath & 'Department of Child & S. Kotecha: Dept of Child kotechas@cardiff.ac.uk \\
Chakraborty, & Health, Cardiff University, & Health, School of Medicine, \\
Sailesh Kotecha & Cardiff University, Cardiff, \\
& $\begin{array}{l}\text { Cardiff } \\
\text { 'Department of }\end{array}$ & CF14 4XN, UK \\
& $\begin{array}{l}\text { Neonatology, University } \\
\text { Hospital of Wales, Cardiff, }\end{array}$ & \\
& UK
\end{tabular}

\section{Pulmonary surfactant in newborn infants and children}

\section{Educational aims}

- To understand the composition, secretory pathways and functions of pulmonary surfactant.

- To review the clinical evidence regarding the use of surfactants in newborn infants and children.

- To develop an understanding of rarer disorders of surfactant metabolism.

- To understand recent developments and future prospects in the field of surfactants.

\section{Summary}

Pulmonary surfactant is a complex mixture of specific lipids, proteins and carbohydrates, which is produced in the lungs by type II alveolar epithelial cells. The mixture is surface active and acts to decrease surface tension at the air-liquid interface of the alveoli. The presence of such molecules with surface activity had been suspected since the early 1900 s and was finally confirmed in the mid-1900s. Since then, the chemical, physical and biological properties of the surfactant mixture have been revealed due to the work of several groups of investigators.

The surfactant mixture is an essential group of molecules to support air breathing. Thus, preterm infants, who are born with immature lungs and are surfactant deficient, develop respiratory distress syndrome after being born. Replacement of natural surfactant therapy with purified surfactant from lungs of nonhuman species is one of the most significant advances in neonatology and has resulted in improved limits of viability of preterm infants. Although preterm infants are the primary population, exogenous surfactant treatment may also have a role to play in other respiratory diseases of term-born infants and older children.
Statement of Interest M. Chakraborty was supported by SPARKs, Medical Research Charity. 


\section{Introduction and historical background}

\section{Definition}

Pulmonary surfactants are a complex of specific lipids, proteins and carbohydrates secreted by type II alveolar epithelial cells. The complex is amphiphilic (i.e. it contains both hydrophobic and hydrophilic groups), making it ideally suited as a surface-active agent to decrease surface tension at the airliquid interface in the alveoli during the respiratory cycle. For the purposes of this review, surfactant will be used to mean mammalian pulmonary surfactant.

\section{Early history}

In 1929, Kurt von Neergaard put forward the idea that the "retractile forces of the lungs depend on surface tension in the alveoli, and this could be the cause of atelectasis in the newborn lungs." [1] In elegant experiments conducted on lung specimens from stillborn and newborn infants dying within 3 days after birth (six out of 15 had a low birth weight), GRUENWALD [2] demonstrated that atelectatic lungs were more difficult to inflate with air than with fluid and required higher pressures. On addition of amyl acetate, a surface-active agent, the inflation pressure was reduced, suggesting that surface tension was the cause of the resistance to inflation. These observations were confirmed in experiments on ex vivo lungs of preterm infants dying of hyaline membrane disease (HMD; pathological description of respiratory distress syndrome, see later). These lungs could be expanded in the presence of liquid, but developed atelectasis with areas of overdistension when expanded in air [3]. PATTLE [4] provided evidence of a lining layer in the alveoli that decreases surface tension, while conducting experiments on the stability of bubbles. He demonstrated that this layer could not have originated from serum (or pulmonary oedema fluid) but must be secreted in the lungs. While researching anti-foam agents to prevent pulmonary oedema, PATTLE [5] conducted detailed experiments to show the physical property of lung fluid in lowering surface tension. $\mathrm{He}$ also demonstrated the presence and importance of protein components in the lung fluid, which lost its surface-active properties on incubation with pancreatin or trypsin. Using a modified Wilhelmy balance (a model to study surface films), AVERY [1] and colleagues demonstrated that surface tension in lung extracts of premature infants dying of HMD had higher surface tension compared to more mature infants, children or adults. They suggested that this could be a significant factor in the pathogenesis of HMD.

The alveolar lining fluid of cows was extracted by PATTLE and ThOMAs [6], and was noted to contain mainly lecithin and gelatine, with a small percentage of protein. Using the extraction method suggested by BONDURANT and Miller [7], Clements [8] and colleagues extracted alveolar lining fluid from bovine lungs. They demonstrated a more complex mixture of lipids and proteins belonging to three different categories: unsaturated phospholipids (the surface-active component), nonphosphorylated lipids and proteins as the skeleton. The first demonstration of the surfactant film by electron microscopy was reported by WEIBEL and GIL [9], who used separate fixation methods to preserve the layer during processing. Since then, several other researchers have continued to investigate the composition and properties of pulmonary surfactant $[10,11]$.

\section{Structure of surfactant}

\section{Extraction of surfactant}

Pulmonary surfactant exists in two major pools: intracellular and extracellular. Most of our knowledge of this complex is derived from studying the extracellular pool secreted by type II alveolar epithelial cells into the alveolar space. Intracellular surfactant pools (lamellar bodies) show similarity to the alveolar components, when studied [12]. Since steps involved in the extraction and purification of pulmonary surfactant can affect the composition of the mixture, the purification process needs to be carefully considered while interpreting results of studies [13]. Previous sources of pulmonary surfactant (pulmonary oedema foam [3]) have been replaced by fractionated lung homogenates and alveolar washes for extraction, followed by density gradient centrifugation for purification of the components [14]. 


\section{Composition}

Mammalian surfactant, extracted by bronchoalveolar lavage and purified by centrifugation, shows similarity in its chemical composition in various species. Figure 1 shows the composition of bovine surfactant, representative of mammalian pulmonary surfactant, containing $80-$ $85 \%$ phospholipid, $5-10 \%$ neutral lipids and 5-10\% surfactant apoproteins [16]. Phosphatidylcholine (PC) is the major phospholipid component of mammalian surfactant and is the primary constituent responsible for lowering surface tension in the alveoli. The majority of the PC in mammalian surfactant is present as the palmitoyl-PC, either with disaturated palmitic acid acyl groups (dipalmitoylphosphatidylcholine (DPPC)) or disaturated PC. It is now clear that DPPC is the primary surface-active molecule at the airfluid interface in the alveoli, with phosphatidylglycerol (PG) probably playing a secondary role [16]. The precise functions of other phospholipids (phosphatidylethanolamine, phosphatidylinositol, phosphatidylserine and sphingomyelin) and neutral lipids (cholesterol and diacylglycerol) are yet to be elucidated [15].

\section{Structure of lipid components}

Since PCs are the main surface-active components of surfactant and as surface tension is a result of difference in attraction of molecules at an interface, the chemical structure of the $P C s$ is an important determinant of their function. PC and PG consist of a three-carbon backbone, with a hydrophilic head group (choline or glycerol) that interacts with the fluid phase and a strongly hydrophobic lipid side-chains (acyl groups). The side chain in DPPC is palmitic acid, which is fully saturated (hydrogenated). Saturation of the acyl chain enables the molecule to form ordered monolayers and confers the ability to be compressed firmly (during expiration, a property essential to decrease surface tension at low lung volumes). Mono- or di-unsaturation produces "kinks" in the molecule that make it less amenable to compression during respiration. This makes DCCP the ideal molecule to lower surface-tension in the alveoli $[15,16]$.

\section{Structure of protein components}

Between $5-10 \%$ of surfactant (weight/weight) consists of protein components [16], which are a mixture of both serum and non-serum proteins. Currently, the existence of four separate non-serum surfactant-associated proteins has been established. These are termed surfactant protein (SP)-A, SP-B, SP-C and SP-D. Although the genetic origin and functions of these proteins have been clarified, the abundance of each protein in the surfactant complex is not known with certainty [15].

SP-A is a $26-35-k D a$ glycoprotein belonging to a family of mammalian C-type lectins containing collagen regions, called collectins [17]. It is synthesised from two genes in humans, SFTPA 1 and SFTPA2, on the long arm of chromosome 10. In the mature hydrophilic protein, the amino-terminus consists of an extensive collagen-like region with a globular carboxyl-terminus containing carbohydrate recognition domains. The oligomeric form of SP-A consists of hexamers, which possibly remain bound to transforming growth factor- $\beta$ in an inactive state and gets dissociated into the active state on inflammatory stimuli [18]. SP-A binds specifically and avidly to DPPC, suggesting a key role in surfactant homeostasis [19]. At least eight different candidate receptors and binding proteins for SP-A are known, of which some are exclusively expressed on alveolar type II cells [17], with new ones being proposed [20].

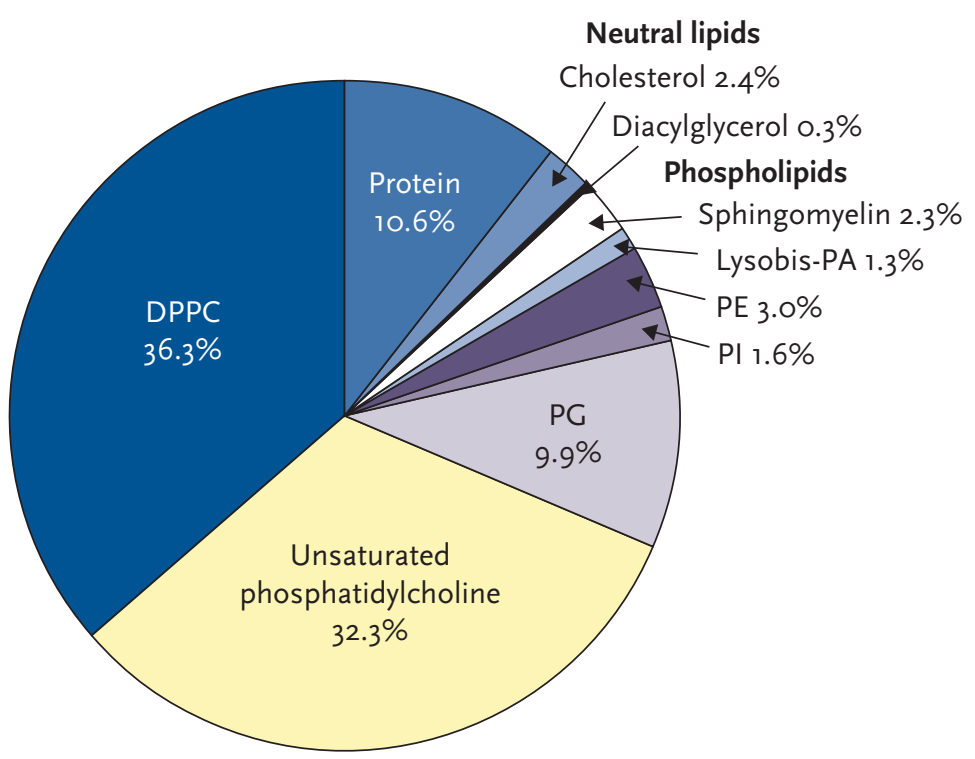

Figure 1

Composition of surfactant. Representative composition of bovine surfactant from lung lavage fluid is shown. Components are expressed as a percentage of weight. DPPC: dipalmitoylphosphatidylcholine; PA; phosphatidic acid; PE: phosphatidylethanolamine; PG: phosphatidy/glycerol; PI: phosphatidylinositol. Reproduced from [15] with permission from the publisher. 
Although the lungs are the primary site of SP-A synthesis, the protein has been shown to be present in other tissues, including intestinal, endocrine and middle ear tissues [17]. This could be related to its role as host defence protein in mammals.

SP-D is a $43-\mathrm{kDa}$ collectin synthesised by the SFTPD gene on the long arm of chromosome 10, in close proximity to the SP-A genes. The general structure of the mature protein is similar to that of SP-A, but the oligomeric form consists of trimers and other high-order complexes [15]. SP-D binds to the minor surfactant components phosphatidylinositol and glucosylceramide [21], and thus its role in surfactant homeostasis is not clear. Three candidate receptors for SP-D have been described, which are shared with SP-A, but none is expressed on the alveolar epithelial type II cells. There is a wide distribution of expression of SP-D in mammalian cells, probably in keeping with its role as an immune defence molecule [17].

SP-B is a 79-amino acid (aa) hydrophobic polypeptide synthesised by the SFTPB gene on chromosome 2, and always remains associated with surfactant phospholipids. Its oligomeric form consists of dimers and tetramers [22].

SP-C is the most hydrophobic protein in surfactant, consisting of 35 aa synthesised by the SFTPC gene on chromosome 8 [15]. The nuclear magnetic resonance structure of SP-C suggests it is a transmembrane protein, which can span a fluid DPPC bilayer [22].

\section{Life cycle of pulmonary surfactant}

\section{Epithelial development}

The development of the lung during organogenesis starts at around 3-4 weeks of gestation as a bud from the foregut; further development proceeds in five distinct stages that overlap at their ends [23]. At the end of the second stage (pseudoglandular), at 16 weeks of gestation, the tracheobronchial tree is complete and is lined by undifferentiated epithelium surrounded by mesenchyme. During the third, or canalicular, stage of development, the respiratory bronchioles and alveolar ducts develop, and the epithelium lining them differentiates into type I and type II cells. Lamellar bodies (see later) and surfactant protein can be detected in the cuboidal type II epithelial cells at around 24 weeks of gestation. These cells are rich in glycogen, which possibly act as a precursor of surfactant phospholipids, and have all the organelles required for the synthesis of surfactant. Further development of the epithelium and secretion of surfactant, and increased complexity of the airspaces, proceeds in the final stages of lung development, vis-à-vis the saccular and alveolar stages. Surfactant secreted into the airspaces in utero can be detected in amniotic fluid in later gestation, and was the basis of a clinical test to detect lung maturity [24].

\section{Surfactant synthesis, secretion and recycling}

Stages in the life cycle of surfactant are depicted in figure 2 [13]. Biosynthesis and processing of surfactant phospholipids and proteins take place in the endoplasmic reticulum and Colgi bodies of the type II alveolar epithelial cells. These molecules are then transported and stored (except SP-A) in structures called lamellar bodies, probably after going through immature stages called multivesicular bodies and composite bodies [25]. Lamellar bodies are lysosome-like organelles consisting of a limiting bilayer membrane with phospholipid bilayer sheets, thin rim and a central core of granular material. During exocytosis, the limiting membrane of the lamellar body fuses with the plasma membrane of the epithelial cell, which results in the contents being poured out into the alveolar space [26]. The phospholipid-rich contents associate with surfactant proteins, especially SP-A, and assemble into a lungspecific structure called tubular myelin, which acts as a reservoir of surfactant during alveolar respiration and enhances the insertion of lipids into the air-liquid interface. The steps involved in the formation of tubular myelin are not fully understood, but it is calcium dependent, as demonstrated by disassembly of tubular myelin in the presence of the calcium chelator ethylene glycol tetraacetic acid [25]. During air breathing, the surfactant film is subjected to high pressures at low lung volumes, which promotes desorption of surfactant lipid. Part of this desorbed lipid is recycled by the type II cells, where they are endocytosed through multivesicular 
bodies, ultimately being stored in lamellar bodies for secretion [25]. Other parts can be recycled extracellularly into tubular myelin, while the rest is taken up by macrophages for degradation. Recycling of surfactant is thought to be part of the explanation for the lasting effects of exogenous surfactant replacement in preterm infants.

\section{Functions of surfactant}

\section{Lipid components}

The primary function of the lipid component of surfactant is to lower surface tension in the alveoli at the air-liquid interface. Stated simply, surface tension is the result of forces of attraction (pressure difference) between molecules at a surface. For fluids, the higher the pressure difference (force of attraction), the higher their surface tension. To minimise the surface tension, the most stable state is when the surface area is the lowest, which is a sphere for fluids. This is related by the Young and Laplace's formula: $\Delta P=2 \gamma / r$, where $\Delta P$ is the pressure difference, $\gamma$ is the surface tension and $r$ is the radius of the sphere. The surface tension of a certain liquid can be altered by adding a second liquid that reduces the attractive forces. At the surface of the mixture of fluids, some molecules with high attractive forces are replaced with others with lower attractive forces, thus lowering the surface tension.

Phospholipids in surfactant, being amphipathic molecules, form a monolayer at the air-liquid interface, where they displace water molecules from the surface to lower tension. The closer this monolayer is packed, the more they displace water and the lower the surface tension. This is what happens at low lung volumes, as in end expiration. Phospholipids with saturated side chains like DPPC can form highly ordered and closely packed films for prolonged periods of time, while unsaturation prevents such close packing [16]. Thus, DPPC is considered the ideal surfactant molecule for lowering alveolar surface tension.

\section{Protein components}

Lipid molecules can change phase from a liquid state to a gel state. The critical temperature at which this phase change occurs is called $T_{c}$. For DPPC, the $T_{c}$ is

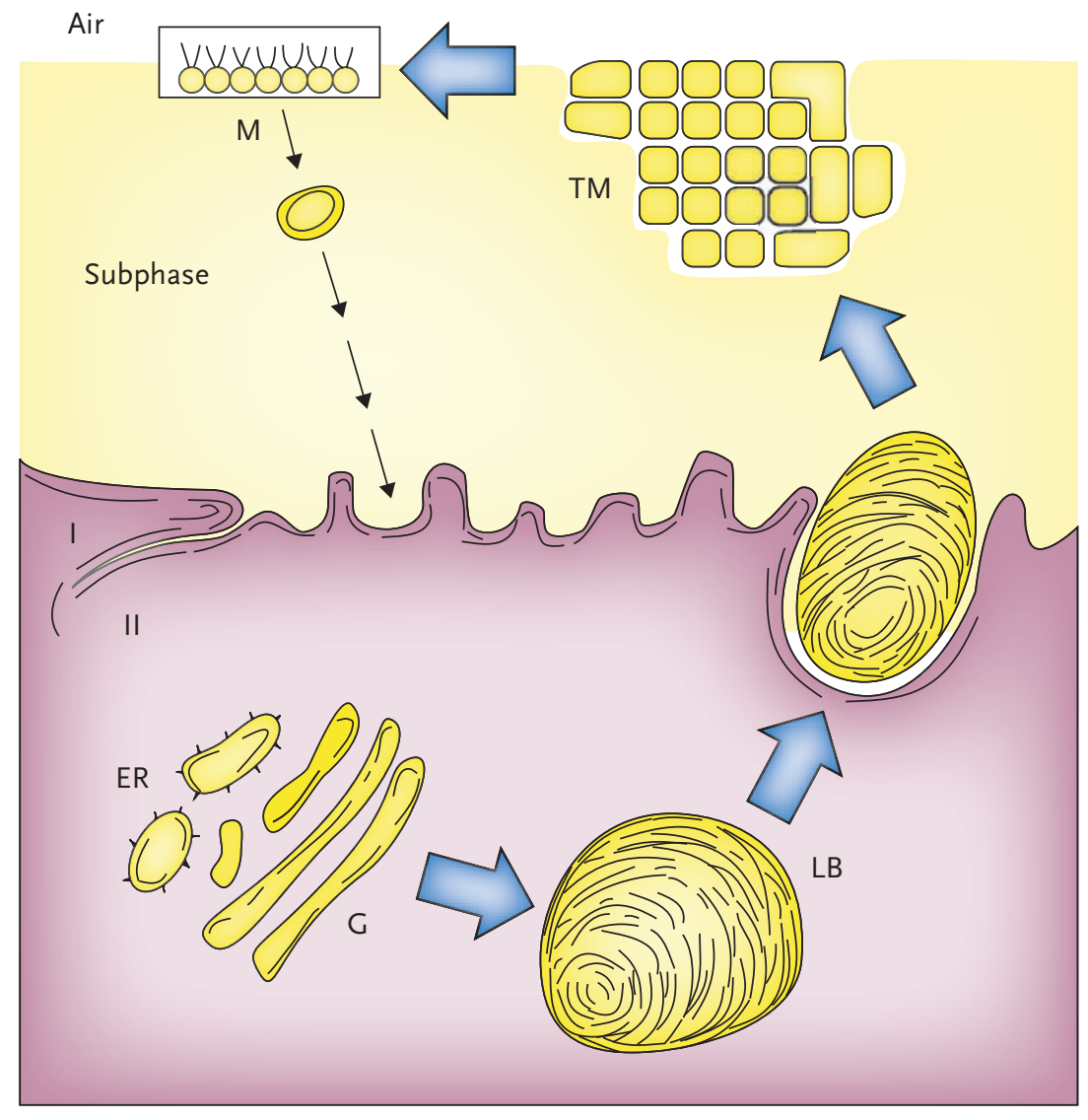

Figure 2

Biological life cycle of pulmonary surfactant in alveolar type II cells. For further details, including recycling of surfactant, see the main text. ER: endoplasmic reticulum; G: Golgi bodies; LB: lamellar bodies; TM: tubular myelin; M: monolayer; I: type I alveolar epithelial cell; II: type II alveolar epithelial cell. Reproduced from [13] with permission from the publisher.

$41^{\circ} \mathrm{C}$; thus, pure DPPC is in a gel state below this temperature, precluding spread of the monolayer in the alveoli to form a surfaceactive film. The clinical implication of this property is that, although DPPC is chemically the ideal surfactant phospholipid, it lacks the physical properties for lowering surface tension to lower values at body temperature $\left(37^{\circ} \mathrm{C}\right)$.

NOTTER et al. [27] showed that a mixture of saturated and unsaturated phospholipids confers favourable adsorption properties. However, they clearly demonstrated the importance of the protein components of surfactant for adsorption, in the presence of calcium. Both SP-B and SP-C greatly enhance the adsorption of DPPC containing mixtures, with SP-B having an effect that is close to natural surfactant [22]. Under experimental conditions, they also confer physical properties to surfactant films to facilitate their ability to attain low surface tension under 
compression. Re-spreading of the compressed surfactant film during respiration is also facilitated by the hydrophobic proteins SP-B and SP-C. SP-A is closely involved in film formation of phospholipid mixtures containing SP-B, in a calcium-dependent manner. However, the exact mechanism by which each of these molecules exerts its action is not known yet.

Apart from the physical effects on surfactant, the collectin SP-A has a critical role in host defence [17]. It enhances the binding, phagocytosis and killing of several bacterial, viral and fungal pathogens. Similarly, SP-D has a carbohydrate recognition domain that can bind and agglutinate bacteria, viruses and fungi. No role for surfactant homeostasis has been demonstrated for SP-D. Thus, the collectins in surfactant, SP-A and SP-D, have important host defence functions in the lung.

\section{Clinical use of surfactant in newborn infants}

\section{Neonatal respiratory distress syndrome}

Respiratory distress syndrome (RDS) is the prototypical disease of surfactant deficiency in preterm newborn infants. Infants born at the extremes of viability ( $\leqslant 28$ weeks gestational age) have immature lungs with severe deficiency of surfactant production. After birth, they need respiratory support and are said to develop RDS. This is characterised primarily by a combination of clinical (prematurity and respiratory distress) and radiological (small volume lungs, "ground-glass" haziness, air bronchograms and loss of cardiac borders on chest radiographs; fig. 3) features. Other names in use for this condition are surfactant deficiency disorder and HMD.

After the discovery of surface-active agents in the 1950s, AVERY [1] and colleagues noted that the lungs of preterm infants dying of HMD had higher surface tension compared to more mature infants and children. After two decades of research into the physical and chemical properties of surfactant (see Early History) and trials on animal models [28], exogenous surfactant replacement was first used on human preterm infants in Japan [29]. Although this was an observational study, it was followed by several randomised controlled trials (RCTs)

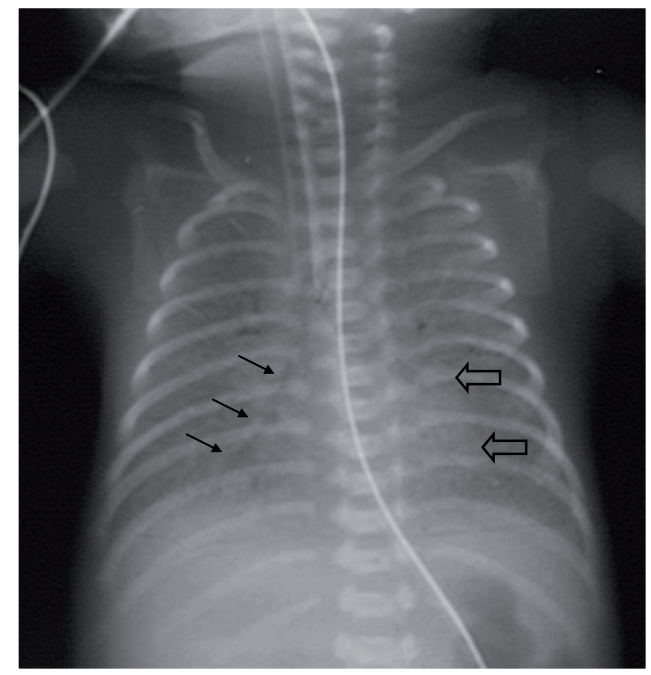

Figure 3

Neonatal respiratory distress syndrome (RDS). Chest radiograph of neonatal respiratory distress syndrome with generalised "ground-glass" opacification of the lung fields bilaterally, air-bronchograms (small arrows) and loss of cardiac borders (open block arrows). Endotracheal and nasogastric tubes are in situ. Image courtesy of S. Barr, University Hospital of Wales, Cardiff, UK (personal collection).

in the next decade, which confirmed the clinical benefits of reduced mortality and morbidity in preterm infants $[30,31]$.

The majority of the clinical trials on the use of prophylactic surfactant in preterm infants were conducted in the era when neither antenatal corticosteroids nor modern noninvasive respiratory support modes like continuous positive airway pressure (CPAP), were in routine use. A meta-analysis of the trials concluded that in infants $<30$ weeks of gestational who were intubated soon after birth in the delivery room or before the onset of clinical RDS, use of prophylactic natural (animal lung or human amniotic fluid) surfactant resulted in significant reduction of the occurrence of pneumothoraces, pulmonary interstitial emphysema, neonatal mortality, and the combined outcome of bronchopulmonary dysplasia (BPD) at 28 days of age or death, compared to a placebo control group [32]. A total of nine RCTs that recruited 1256 infants were included in this meta-analysis. Prophylactic artificial (protein free) surfactants in preterm infants at risk of RDS also resulted in a reduced risk of neonatal mortality and air leak syndromes when compared to placebo, although all of the trials included in this review were conducted before the widespread 
use of antenatal corticosteroids or early CPAP [33]. Results of the use of protein-containing artificial surfactants as prophylaxis or treatment of RDS (two trials) were comparable to animal-derived natural surfactants [34]. Trials comparing prophylactic (before the onset of clinical RDS) versus selective (after observing clinical signs of RDS) use of surfactant (all of natural origin) in preterm infants $<30$ weeks of gestational age, before the widespread use of antenatal corticosteroids or CPAP, reported a significant reduction in the risk of neonatal mortality, the combined outcome of BPD or death at 28 days, and pulmonary air leaks [35]. However, when comparing these two strategies in trials involving infants who had the benefit of antenatal corticosteroids and routine early CPAP to control infants $[36,37]$, the above benefits were less clear. On the contrary, use of prophylactic surfactant was associated with a significant increase in the risk of BPD at 28 days and the combined outcome of BPD or death at 28 days [35]. Using natural surfactants (animal derived) for treatment of RDS resulted in a significantly reduced risk of mortality and pneumothoraces [38] when compared with artificial surfactants [39], although the artificial surfactants did show clinical benefits [40]. After the onset of clinical RDS, trials comparing early (prophylactic) use of surfactant (both natural and synthetic) demonstrated a significant reduction in the risk of neonatal mortality, BPD at 36 weeks corrected gestational age, the combined outcome of BPD or death at 36 weeks corrected gestational age, and air leak syndromes (pneumothorax and pulmonary interstitial emphysema), when compared with the late (rescue) use of surfactant (on worsening of RDS) [41]. Multiple doses of surfactant result in significant reduction in the risk of pneumothorax and mortality in ventilated preterm infants with RDS, when compared with a single dose of surfactant [42]. However, the majority of the infants involved in this comparison did not have the benefit of antenatal corticosteroids. The strategy of early use of surfactant followed by planned extubation (to noninvasive respiratory support) in preterm infants with clinical signs of RDS results in a decreased risk of the need for mechanical ventilation, BPD at 28 days of age and air leak syndromes when compared to surfactant administration and prolonged mechanical ventilation [43].
In summary, any exogenous surfactant replacement, as prophylaxis or for rescue treatment of RDS, results in important clinical benefits. Natural surfactants (animal or human amniotic fluid) seem to be clinically superior to current synthetic surfactants. After the onset of RDS, the earlier surfactant is used, the better the outcomes. The strategy of early surfactant administration followed by extubation of preterm infants with RDS seems to have better outcomes when compared to prolonged ventilation after surfactant administration.

\section{Neonatal meconium aspiration syndrome}

Meconium aspiration in term or near-term infants has severe respiratory consequences, including mechanical obstruction of the airways [44], changes in pulmonary gas exchange and compliance [44] and surfactant inactivation [45] due to a chemical pneumonitis [46]. Infants with severe meconium aspiration syndrome (MAS) develop persistent pulmonary hypertension and may require temporary support with lung bypass strategies, called extracorporeal membrane oxygenation (ECMO) [47]. Four randomised controlled clinical trials have explored the efficacy of using high-dose pulmonary surfactant in term or near-term infants with MAS. A meta-analysis of the studies reported a significant reduction in the risk of treatment with ECMO compared with standard care, although other important outcomes, like mortality, air leaks, BPD and intraventricular haemorrhage, were not different between the two groups [48]. Two trials have used a strategy of lung lavage with dilute surfactants for the treatment of MAS. A meta-analysis of these two trials concluded that this strategy significantly reduced the combined risk of death or need for ECMO compared with a placebo control group [49]. However, other important clinical outcomes were not significantly different between the two groups, although the total number of infants involved in the trials was small. In a recent comparative trial of lung lavage versus bolus dose of surfactant in an animal model of MAS, the former group (lavage) demonstrated significantly improved ventilation characteristics and pulmonary arterial pressures [50]. This therapy may be of benefit in the future, as

\section{Educational questions}

1. The molecule best suited for surface activity at the air-liquid interface in the alveoli is:
a. SP-B
b. $P G$
c. DPPC
d. sphingomyelin
e. SP-A

2. The most common use for exogenous surfactant in humans is in:
a. ARDS
b. RDS
c. MAS
d. group B strep-
tococcal sepsis

e. bronchiolitis

3. Currently, the best time to replace surfactant in preterm infants with neonatal RDS:

a. is before the onset of RDS (prophylactic)

b. is at the onset of RDS (early rescue)

C. is only when RDS gets worse with increasing ventilatory requirements (late rescue)

d. never, as surfactant replacement is not indicated in RDS

e. remains controversial, and a topic of research

4. According to current research, which of the following is the most effective exogenous surfactant replacement for neonatal RDS?

a. Poractant alfa

b. Endogenous human (from amniotic fluid)
c. Colfosceril
d. Lucinactant 
suggested by the results of nonrandomised trials.

\section{Group B Streptococcus sepsis in newborn infants}

Acute respiratory distress syndrome due to group B streptococcal (GBS) sepsis can cause surfactant dysfunction by mechanisms similar to MAS. In addition, due to inflammatory injury of the alveolar epithelial surface leading to compromise of the air-fluid barrier, there is leakage of fluid (alveolar oedema) and serum proteins into the airspace. Both alveolar oedema [51] and serum proteins [52] can contribute to surfactant inactivation and dysfunction. Efficacy of exogenous surfactant replacement therapy in acute respiratory failure due to GBS sepsis was studied in a prospective multicentre trial [53]. Treatment with surfactant resulted in a rapid decrease in oxygen requirements, although other morbidities and mortality were high overall.

\section{Surfactant use in children}

Acute respiratory distress syndrome (ARDS) due to acute lung injury in children and adolescents can cause surfactant dysfunction by the same mechanisms as discussed above. In a large RCT of exogenous natural surfactant replacement in children with ARDS, the authors found a significant decrease in oxygen requirements and mortality in the treatment group, compared with the placebo control group [54]. Improvement in ventilation characteristics were noted in several nonrandomised trials of exogenous surfactant therapy in children with ARDS [55], although the number of patients in each study were small. Overall, there seem to be short-term benefits in exogenous surfactant, although further larger trials are warranted.

Bronchiolitis is a common viral respiratory infection of infants and young children, and the most common pathogen is respiratory syncytial virus (RSV). A small number of patients with bronchiolitis progress to respiratory failure needing ventilatory support. Three small RCTs have studied the effects of exogenous surfactant replacement in children with respiratory failure due to bronchiolitis. A meta-analysis of the studies found that use of surfactant significantly reduced the duration of mechanical ventilation and intensive care stay; and improved ventilation characteristics (oxygenation and elimination of carbon dioxide)
[56]. However, due to the small numbers of infants included in the trials, this remains an experimental therapy for the treatment of respiratory failure in bronchiolitis.

In summary, the most common and best studied application for surfactants is in preterm neonatal RDS. Some controversies remain regarding the use of surfactants in this population, including the timing of the first dose, indications for multiple doses and the use of newer synthetic surfactant preparations (table 1) [57]. Surfactants have been used for other indications in neonates and children, and have achieved short-term benefits. However, further work is required to clarify the role of surfactants for non-RDS diseases.

\section{Genetic defects of surfactant proteins}

Of the four known surfactant proteins, the hydrophobic SP-B and SP-C are essential for normal surfactant function in the lungs. Although not directly involved in lowering surface activity, another protein that has been identified on the limiting membrane of lamellar bodies is adenosine triphosphatebinding cassette $A_{3}\left(A B C A_{3}\right)$ [58]. $A B C A_{3}$ is thought to be an intracellular transporter for lipid molecules of surfactant into the lamellar bodies. Thyroid transcription factor (TTF)- 1 is involved in development of the lung and expression of surfactant proteins during foetal life [59]. Thus, genetic mutations of the TTF-1 gene $N K X_{2.1}$ can result in lung diseases in newborn infants which mimic RDS.

Among all the known genetic diseases of surfactant metabolism, defects of SP-B are the best studied. Although over 30 mutations have been identified in SFTPB, the most common one is a substitution of three bases, GAA, for $C$ at codon 121 on exon 4. This is termed 121 ins2 and accounts for about $70 \%$ of the mutations resulting in SP-B deficiencies [6o]. Several other mutations have been identified, all of which result in loss of function of the gene [61]. The best estimate of the incidence of 121ins2 mutation in the population is 1 in 1000-3000 [62], suggesting a total rate of any mutation of about 1 in 6001800 . Since any SP-B deficiency is autosomal recessive, the predicted incidence of this disorder is very rare. Mutations resulting in partial deficiency of SP-B have been described, which lead to chronic disease [61]. Surfactant 
TABLE 1 Sources and components of lung surfactants

\begin{tabular}{|c|c|c|c|c|c|}
\hline Beractant & Survanta & Bovine & $25 \mathrm{mg} \cdot \mathrm{mL}^{-1}(50 \% \mathrm{DPPC})$ & SP-B, SP-C & USA \\
\hline Calfactant & Infasurf & Bovine & $35 \mathrm{mg} \cdot \mathrm{mL}^{-1}(74 \% \mathrm{DPPC})$ & SP-B, SP-C & USA \\
\hline Poractant alfa & Curosurf & Porcine & $\begin{array}{c}80 \mathrm{mg} \cdot \mathrm{mL}^{-1}(70 \% \\
\mathrm{DPPC})\end{array}$ & SP-B, SP-C & Italy \\
\hline Bovactant & Alveofact & Bovine & $50 \mathrm{mg} \cdot \mathrm{mL}^{-1}$ & SP-B, SP-C & Germany \\
\hline BLES & bLES & Bovine & $27 \mathrm{mg} \cdot \mathrm{mL}^{-1}$ & SP-B, SP-C & Canada \\
\hline $\begin{array}{l}\text { Endogenous human } \\
\text { surfactant }\end{array}$ & & Amniotic fluid & $20 \mathrm{mg} \cdot \mathrm{mL}^{-1}$ & SP-A, SP-B, SP-C & USA/ Netherlands \\
\hline Lucinactant & Surfaxin & Synthetic & $30 \mathrm{mg} \cdot \mathrm{mL}^{-1}(75 \% \mathrm{DPPC})$ & Sinapultide & USA \\
\hline
\end{tabular}

replacement results in small improvement of clinical status, but this is short-lived [61].

Although SP-C is closely involved in surfactant metabolism in the lungs, mutations of SFTPC do not usually result in a severe phenotype. The mutations are usually inherited in a dominant fashion, and their incidence is not known. Deficiencies of SP-C have been implicated in interstitial lung disease (ILD) in children [63].

The other protein deficiency leading to surfactant dysfunction is that of $A B C A 3$. Although the precise function of this protein is not yet established, $A B C A_{3}$ gene mutations were identified in newborns with severe lung disease and surfactant deficiency [64]. The presence of abnormal lamellar bodies in these infants suggested the role of $\mathrm{ABCA}_{3}$ as a transporter protein. Several mutations have been reported for $A B C A_{3}$, with a substitution of valine for glutamic acid at codon 292 being identified as the most common [65]. Severe neonatal hypoxic respiratory failure is the usual phenotype of $\mathrm{ABCA}_{3}$ deficiency [64], although a more chronic course with ILD is also known [61].

Dominantly expressed mutations of $N K X_{2.1}$ have been reported to cause a syndrome involving choreoathetosis, hypothyroidism and chronic lung involvement (respiratory distress in the newborn period or repeated infections in later childhood) [66]. The respiratory component could range between acute neonatal RDS to chronic childhood ILD. Several mutations have been identified, resulting in a wide variety of phenotypes [67].

Although several genetic defects resulting in deficiency of surfactant proteins quantity or function have been identified, currently no specific treatment exists for any of them. SP-B deficiencies are the most severe, and often carry poor prognosis. However, some forms of SP-B deficiency have been reported (compound heterozygotes and splice mutations) with prolonged survival $[68,69]$. Presentation of the other genetic defects can be clinically variable. Lung transplantation has been performed for several of these disorders and resulted in a 5-year survival rate (fig.4) of approximately 50\% [61, 70]. However, lung transplantation is associated with many complications and, thus, should be confined to experienced specialist centres.

\section{Recent developments and future trends}

Currently, administration of surfactant to newborn infants and children requires 

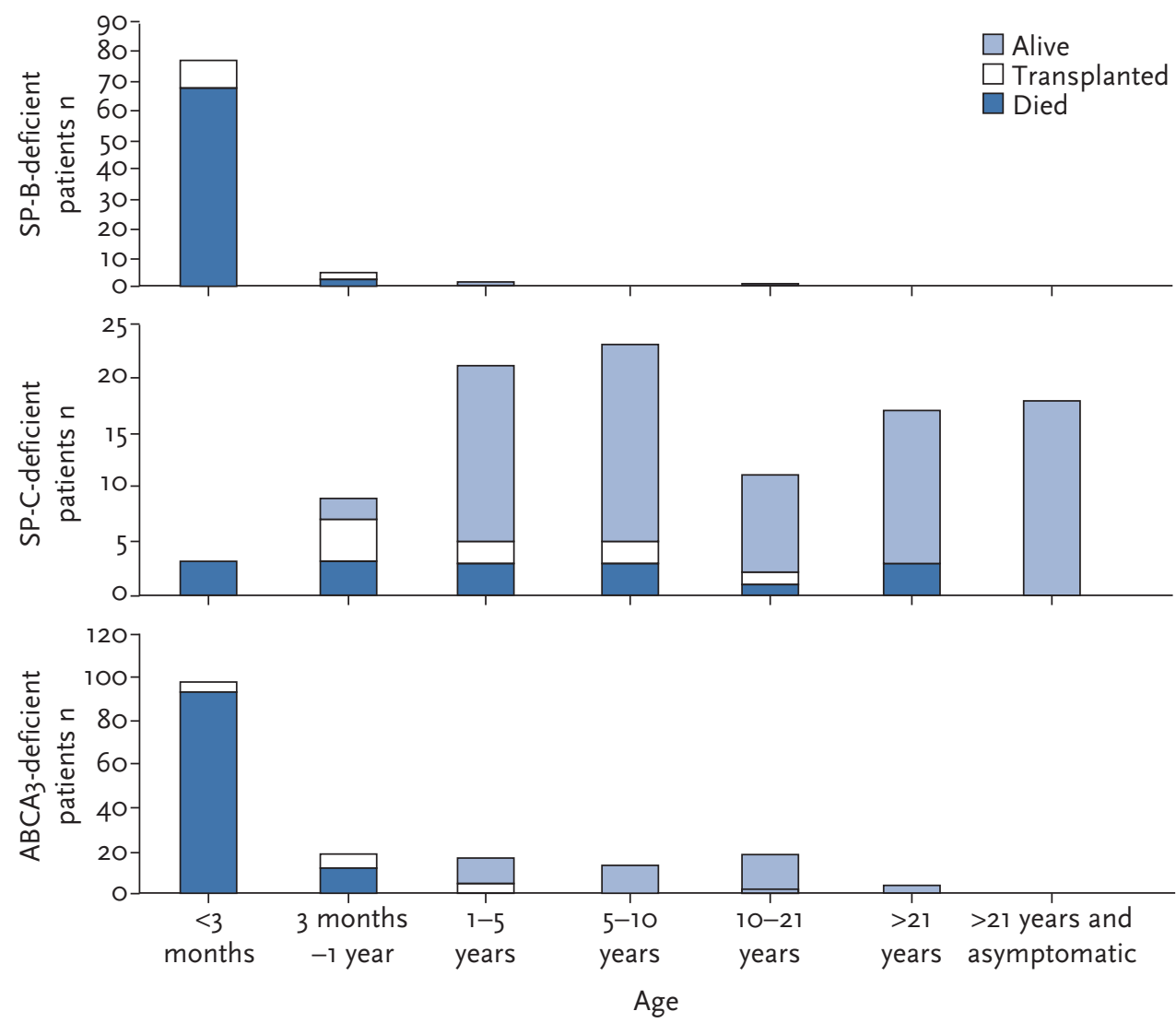

Figure 4

Lung transplantation in surfactant protein deficiencies. Long-term outcomes of whole-lung transplantation in children with inherited surfactant protein deficiencies. SP: surfactant protein; ABCA: adenosine triphosphate binding cassette. Reproduced from [70] with permission from the publisher.

intubation and mechanical ventilation. As this treatment is most commonly used in preterm infants at risk of or with established RDS, this becomes an invasive procedure. Mechanical ventilation itself can result in lung injury [71], and noninvasive modes of ventilation are becoming more prevalent [72]. Thus, less invasive methods of surfactant delivery are being trialled. First reported in Germany [73], surfactant delivery through a thin endotracheal catheter in spontaneously breathing infants seems to limit the need for mechanical ventilation and reduce the incidence of BPD [74, 75]. In a variation of this method, DARCAVILLE et al. [76] delivered surfactant to spontaneously breathing infants on CPAP (after premedication) through a vascular catheter. Although this method has theoretical benefits, further research will be needed on RCTs to clarify the clinical effects of such a strategy for surfactant delivery.

Another noninvasive way of delivering surfactant is by nebulisation. Several reports of nebulised surfactant in spontaneously breathing preterm infants have been published [77]. Unfortunately, due to significant differences in methods used, these are not comparable. Although nebulisation seems to be a feasible procedure, further research is needed to standardise methods, doses, clinical efficacy and safety before it becomes established in clinical practice [78].

\section{Conclusion}

Surfactants are natural complexes of phospholipids and proteins that are present at the air-liquid interface of the lungs to lower surface tension. Replacement with exogenous surfactant in preterm infants is one of the most significant advances in neonatology. Exogenous surfactant therapy may also have a role in other respiratory disorders of the newborn and of older children, but further 
work is required to establish its place. Further research is also required into newer novel methods of its delivery, optimal composition and timing. However, the place of this intervention has been firmly fixed in medicine.
References

1. Avery ME. Historical perspective. In: Polin RA, Fox WW, Abman SH, eds. Fetal and Neonatal Physiology. 4th Edn. Philadelphia, Saunders, 2011; pp. 1082-1084.

2. Gruenwald P. Surface tension as a factor in the resistance of neonatal lungs to aeration. Am J Obstet Gynecol 1947; 53: 996-1007.

3. Tran Dinh DE, Anderson GW. Hyaline-like membranes associated with diseases of the newborn lungs: a review of the literature. Obstet Gynecol Surv 1953; 8: 1-44.

4. Pattle RE. Properties, function and origin of the alveolar lining layer. Nature 1955; 175: 1125-1126.

5. Pattle RE. Properties, function, and origin of the alveolar lining layer. Proc R Soc Lond B Biol Sci 1958; 148: 217-240.

6. Pattle RE, Thomas LC. Lipoprotein composition of the film lining the lung. Nature 1961; 189: 844.

7. Bondurant S, Miller DA. A method for producing surfaceactive extracts of mammalian lungs. J Appl Physiol 1962; 17: 167-168.

8. Clements JA. Surface phenomena in relation to pulmonary function. Physiologist 1962; 5: 11-28.

9. Weibel ER, Gil J. Electron microscopic demonstration of an extracellular duplex lining layer of alveoli. Respir Physiol 1968; 4: 42-57.

10. Miller DA, Bondurant S. Surface characteristics of vertebrate lung extracts. J Appl Physiol 1961; 16: 1075-1077.

11. Bolande RP, Klaus MH. The morphologic demonstration of an alveolar lining layer and its relationship to pulmonary surfactant. Am J Pathol 1964; 45: 449-463.

12. Harwood JL. Lung surfactant. Prog Lipid Res 1987; 26: 211-256.

13. Goerke J. Lung surfactant. Biochim Biophys Acta 1974; 344: 241-261.

14. King RJ, Clements JA. Surface active materials from dog lung. I. Method of isolation. Am J Physiol 1972; 223: 707-714.

15. Whitsett JA. Composition of pulmonary surfactant lipids and proteins. In: Polin RA, Fox WW, Abman $\mathrm{SH}$, eds. Fetal and Neonatal Physiology. 4 Edn. Philadelphia, Saunders, 2011; pp. 1084-1093.

16. Possmayer F, Yu SH, Weber JM, et al. Pulmonary surfactant. Can J Biochem Cell Biol 1984; 62: 1121-1133.

17. Kishore U, Greenhough TJ, Waters P, et al. Surfactant proteins SP-A and SP-D: structure, function and receptors. Mol Immunol 2006; 43: 1293-1315.

18. Bersani I, Speer CP, Kunzmann S. Surfactant proteins $A$ and $D$ in pulmonary diseases of preterm infants. Expert Rev Anti Infect Ther 2012; 10: $573-584$.

19. Kuroki Y, Akino T. Pulmonary surfactant protein A (SP-A) specifically binds dipalmitoyl phosphatidylcholine. J Biol Chem 1991; 266: 3068-3073.

20. Bates SR. P63 (CKAP4) as an SP-A receptor: implications for surfactant turnover. Cell Physiol Biochem 2010; 25: 41-54.
21. Ogasawara Y, Kuroki Y, Akino T. Pulmonary surfactant protein $\mathrm{D}$ specifically binds to phosphatidylinositol. J Biol Chem 1992; 267: 21244-21249.

22. Weaver TE, Conkright JJ. Function of surfactant proteins B and C. Annu Rev Physiol 2001; 63: 555-578.

23. Joshi S, Kotecha S. Lung growth and development. Early Hum Dev 2007; 83:12, 789-794.

24. Gluck L, Kulovich MV, Borer RC Jr, et al. Diagnosis of the respiratory distress syndrome by amniocentesis. Am J Obstet Gynecol 1971; 109: 440-445.

25. Randell SH, Young SL. Structure of alveolar epithelial cells and the surface layer during development. In: Polin RA, Fox WW, Abman SH, eds. Fetal and Neonatal Physiology. 4th Edn. Philadelphia, Saunders, 2011; pp. 1115-1122.

26. Dietl P, Haller T. Exocytosis of lung surfactant: from the secretory vesicle to the air-liquid interface. Annu Rev Physiol 2005; 67: 595-621.

27. Notter RH, Finkelstein JN, Taubold RD. Comparative adsorption of natural lung surfactant, extracted phospholipids, and artificial phospholipid mixtures to the air-water interface. Chem Phys Lipids 1983; 33: 67-80.

28. Enhorning G, Robertson B. Lung expansion in the premature rabbit fetus after tracheal deposition of surfactant. Pediatrics 1972; 50: 58-66.

29. Fujiwara $\mathrm{T}$, Maeta $\mathrm{H}$, Chida $\mathrm{S}$, et al. Artificial surfactant therapy in hyaline-membrane disease. Lancet 1980; 1: 55-59.

30. Schwartz RM, Luby AM, Scanlon JW, et al. Effect of surfactant on morbidity, mortality, and resource use in newborn infants weighing 500 to $1500 \mathrm{~g}$. N Engl J Med 1994; 330: 1476-1480.

31. Jobe AH. Pulmonary surfactant therapy. N EnglJ Med 1993; 328: 861-868.

32. Soll RF. Prophylactic natural surfactant extract for preventing morbidity and mortality in preterm infants. Cochrane Database Syst Rev 2000; 2: CDooo511.

33. Soll R, Ozek E. Prophylactic protein free synthetic surfactant for preventing morbidity and mortality in preterm infants. Cochrane Database Syst Rev 2010; 1: CDoolo79.

34. Pfister RH, Soll RF, Wiswell T. Protein containing synthetic surfactant versus animal derived surfactant extract for the prevention and treatment of respiratory distress syndrome. Cochrane Database Syst Rev 2007; 4: CDoo6069.

35. Rojas-Reyes MX, Morley C), Soll R. Prophylactic versus selective use of surfactant in preventing morbidity and mortality in preterm infants. Cochrane Database Syst Rev 2012; 3: CDooo510.

36. Finer NN, Carlo WA, Walsh MC, et al. Early CPAP versus surfactant in extremely preterm infants. N Engl J Med 2010; 362: 1970-1979.

37. Dunn MS, Kaempf J, de Klerk A, et al. Randomized trial comparing 3 approaches to the initial respiratory management of preterm neonates. Pediatrics 2011; 128: e1069-e1076.

38. Seger N, Soll R. Animal derived surfactant extract for treatment of respiratory distress syndrome. Cochrane Database Syst Rev 2009; 2: CDoo7836.
Answers to educational questions

1. C

2. $b$

3. e

4. a 
39. Soll RF, Blanco F. Natural surfactant extract versus synthetic surfactant for neonatal respiratory distress syndrome. Cochrane Database Syst Rev 2001; 2: CDooo144.

40. Soll RF. Synthetic surfactant for respiratory distress syndrome in preterm infants. Cochrane Database Syst Rev 2000; 2: CDool149.

41. Bahadue FL, Soll R. Early versus delayed selective surfactant treatment for neonatal respiratory distress syndrome. Cochrane Database Syst Rev 2012; 11: CDoo1456.

42. Soll R, Ozek E. Multiple versus single doses of exogenous surfactant for the prevention or treatment of neonatal respiratory distress syndrome. Cochrane Database Syst Rev 2009; 1: CDooo141.

43. Stevens TP, Harrington EW, Blennow M, Soll RF. Early surfactant administration with brief ventilation vs. selective surfactant and continued mechanical ventilation for preterm infants with or at risk for respiratory distress syndrome. Cochrane Database Syst Rev; 2007:4, CDo03063.

44. Tran N, Lowe C, Sivieri EM, Shaffer TH. Sequential effects of acute meconium obstruction on pulmonary function. Pediatr Res 1980; 14: 34-38.

45. Herting E, Rauprich P, Stichtenoth G, Walter G, Johansson J, Robertson B. Resistance of different surfactant preparations to inactivation by meconium. Pediatr Res 2001; 50: 44-49.

46. Tyler DC, Murphy J, Cheney FW. Mechanical and chemical damage to lung tissue caused by meconium aspiration. Pediatrics 1978; 62: 454-459.

47. Ghodrat M. Lung surfactants. Am J Health Syst Pharm 2006; 63: 1504-1521.

48. El Shahed AI, Dargaville P, Ohlsson A, et al. Surfactant for meconium aspiration syndrome in full term/near term infants. Cochrane Database Syst Rev 2007; 3: CDoo2054.

49. Choi HJ, Hahn S, Lee J, Park BJ, Lee SM, Kim HS, Bae $\mathrm{CW}$. Surfactant lavage therapy for meconium aspiration syndrome: a systematic review and metaanalysis. Neonatology 2012: 101; 3: 183-191.

50. Rey-Santano C, Alvarez-Diaz FJ, Mielgo V, et al. Bronchoalveolar lavage versus bolus administration of lucinactant, a synthetic surfactant in meconium aspiration in newborn lambs. Pediatr Pulmonol 2011; 46: 991-999.

51. Kobayashi T, Nitta K, Ganzuka M, et al. Inactivation of exogenous surfactant by pulmonary edema fluid. Pediatr Res 1991; 29: 353-356.

52. Cockshutt AM, Possmayer F.

Lysophosphatidylcholine sensitizes lipid extracts of pulmonary surfactant to inhibition by serum proteins. Biochim Biophys Acta 1991; 1086: 63-71.

53. Herting E, Gefeller O, Land M, et al. Surfactant treatment of neonates with respiratory failure and group B streptococcal infection. Members of the Collaborative European Multicenter Study Group Pediatrics 2000; 106: 957-964.

54. Willson DF, Thomas NJ, Markovitz BP, et al. Effect of exogenous surfactant (calfactant) in pediatric acute lung injury: a randomized controlled trial. JAMA 2005; 293: 470-476.

55. Raghavendran K, Willson D, Notter RH. Surfactant therapy for acute lung injury and acute respiratory distress syndrome. Crit Care Clin 2011; 27: 525-559.

56. Jat KR, Chawla D. Surfactant therapy for bronchiolitis in critically ill infants. Cochrane Database Syst Rev 2012; 9: CDoog194.

57. Sweet DG, Halliday HL. The use of surfactants in 2009. Arch Dis Child Educ Pract Ed 2009; 94: 78-83.

58. Mulugeta S, Gray JM, Notarfrancesco KL, et al. Identification of LBM180, a lamellar body limiting membrane protein of alveolar type II cells, as the
$A B C$ transporter protein $A B C A_{3}$. J Biol Chem 2002; 277: 22147-22155.

59. Boggaram V. Thyroid transcription factor-1 (TTF-1/ $\mathrm{Nk \times 2.1/TITF1)}$ gene regulation in the lung. Clin Sci (Lond) 2009; 116: 27-35.

6o. Nogee LM, Garnier G, Dietz HC, et al. A mutation in the surfactant protein $B$ gene responsible for fatal neonatal respiratory disease in multiple kindreds. J Clin Invest 1994; 93: 1860-1863.

61. Hamvas A. Evaluation and management of inherited disorders of surfactant metabolism. Chin Med J (Engl) 2010; 123: 2943-2947.

62. Cole FS, Hamvas A, Rubinstein P, et al. Populationbased estimates of surfactant protein B deficiency. Pediatrics 2000; 105: 538-541.

63. Beers MF, Mulugeta S. Surfactant protein C biosynthesis and its emerging role in conformational lung disease. Annu Rev Physiol 2005; 67: 663-696.

64. Shulenin S, Nogee LM, Annilo T, et al. ABCA3 gene mutations in newborns with fatal surfactant deficiency. N Engl J Med 2004; 350: 1296-1303.

65. Garmany TH, Wambach JA, Heins HB, et al. Population and disease-based prevalence of the common mutations associated with surfactant deficiency. Pediatr Res 2008; 63: 645-649.

66. Krude $\mathrm{H}$, Schutz B, Biebermann $\mathrm{H}$, et al. Choreoathetosis, hypothyroidism, and pulmonary alterations due to human $N K X_{2-1}$ haploinsufficiency. J Clin Invest 2002; 109: 475-480.

67. Carre A, Szinnai G, Castanet M, et al. Five new TTF1/ $N K X 2.1$ mutations in brain-lung-thyroid syndrome: rescue by PAX8 synergism in one case. Hum $\mathrm{Mol}$ Genet 2009; 18: 2266-2276.

68. Ballard PL, Nogee LM, Beers MF, et al. Partial deficiency of surfactant protein $B$ in an infant with chronic lung disease. Pediatrics 1995; 96: 1046-1052.

69. Dunbar AE 3rd, Wert SE, Ikegami M, et al. Prolonged survival in hereditary surfactant protein B (SP-B) deficiency associated with a novel splicing mutation. Pediatr Res 2000; 48: 275-282.

70. Gower WA, Nogee LM. Surfactant dysfunction. Paediatr Respir Rev 2011; 12: 223-229.

71. Chakraborty M, McGreal EP, Kotecha S. Acute lung injury in preterm newborn infants: mechanisms and management. Paediatr Respir Rev 2010; 11: 162-170.

72. DiBlasi RM, Cheifetz IM. Neonatal and pediatric respiratory care: what does the future hold? Respir Care 2011; 56:9, 1466-1480.

73. Kribs A, Pillekamp F, Hunseler C, et al. Early administration of surfactant in spontaneous breathing with nCPAP: feasibility and outcome in extremely premature infants (postmenstrual age $\leqslant 27$ weeks). Paediatr Anaesth 2007; 17: 364-369.

74. Kribs A, Hartel C, Kattner E, et al. Surfactant without intubation in preterm infants with respiratory distress: first multi-center data. Klin Padiatr 2010; 222: 13-17.

75. Kanmaz HG, Erdeve O, Canpolat FE, et al. Surfactant administration via thin catheter during spontaneous breathing: randomized controlled trial. Pediatrics 2013; 131: e502-e509.

76. Dargaville PA, Aiyappan A, De Paoli AG, et al. Minimally-invasive surfactant therapy in preterm infants on continuous positive airway pressure. Arch Dis Child Fetal Neonatal Ed 2013; 98: F122-F126.

77. Mazela J, Merritt TA, Finer NN. Aerosolized surfactants. Curr Opin Pediatr 2007; 19: 155-162.

78. Abdel-Latif ME, Osborn DA. Nebulised surfactant in preterm infants with or at risk of respiratory distress syndrome. Cochrane Database Syst Rev 2012; 10: CDoo8310. 